\title{
Selective Inhibition of Cyclooxygenase (COX)-2 Reverses Inflammation and Expression of COX-2 and Interleukin 6 in Rat Adjuvant Arthritis
}

\author{
Gary D. Anderson, ${ }^{\star}$ Scott D. Hauser, ${ }^{\ddagger}$ Kelly L. McGarity, ${ }^{\star}$ Margaret E. Bremer, ${ }^{\star}$ Peter C. Isakson, ${ }^{\star}$ and Susan A. Gregory ${ }^{\star}$ \\ Departments of *Inflammatory Diseases Research and ${ }^{\ddagger}$ Cell and Molecular Biology, G.D. Searle \& Company, St. Louis, Missouri 63198
}

\begin{abstract}
Prostaglandins formed by the cyclooxygenase (COX) enzymes are important mediators of inflammation in arthritis. The contribution of the inducible COX-2 enzyme to inflammation in rat adjuvant arthritis was evaluated by characterization of COX-2 expression in normal and arthritic paws and by pharmacological inhibition of COX-2 activity. The injection of adjuvant induced a marked edema of the hind footpads with coincident local production of $\mathrm{PGE}_{2}$. PG production was associated with upregulation of COX-2 mRNA and protein in the affected paws. In contrast, the level of COX-1 mRNA was unaffected by adjuvant injection. TNF- $\alpha$ and IL-6 mRNAs were also increased in the inflamed paws as was IL-6 protein in the serum. Therapeutic administration of a selective COX-2 inhibitor, SC-58125, rapidly reversed paw edema and reduced the level of $\mathrm{PGE}_{2}$ in paw tissue to baseline. Interestingly, treatment with the COX-2 inhibitor also reduced the expression of COX-2 mRNA and protein in the paw. Serum IL-6 and paw IL-6 mRNA levels were also reduced to near normal levels by SC-58125. Furthermore, inhibition of COX-2 resulted in a reduction of the inflammatory cell infiltrate and decreased inflammation of the synovium. Notably, the antiinflammatory effects of SC58125 were indistinguishable from the effects observed for indomethacin. These results suggest that COX-2 plays a prominent role in the inflammation associated with adjuvant arthritis and that COX-2 derived PGs upregulate COX-2 and IL-6 expression at inflammatory sites. (J. Clin. Invest. 1996. 97:2672-2679.) Key words: eicosanoid • cytokine $\bullet$ prostaglandin $\bullet$ cyclooxygenase $\bullet$ inflammation
\end{abstract}

\section{Introduction}

Prostaglandins are important lipid mediators that are produced at elevated levels in inflamed tissues including rheumatoid synovium $(1,2)$. $\mathrm{PGE}_{2}$ and $\mathrm{PGI}_{2}$ likely contribute to synovial inflammation by increasing local blood flow and potentiating the effects of mediators such as bradykinin and IL-1 that induce vasopermeability (reviewed in reference 3). $\mathrm{PGE}_{2}$ has also been shown to trigger osteoclastic bone resorption (4), suggesting that this molecule may contribute to the pathophys-

Address correspondence to Susan A. Gregory, G.D. Searle \& Co., 700 Chesterfield Parkway North/AA5C, St. Louis, MO 63198. Phone: 314-537-7150; FAX: 314-537-7388; E-mail: sagreg@ccmail.monsanto.com

Received for publication 28 November 1995 and accepted in revised form 14 March 1996.

J. Clin. Invest.

(c) The American Society for Clinical Investigation, Inc. 0021-9738/96/06/2672/08 \$2.00

Volume 97, Number 11, June 1996, 2672-2679 iology of joint erosion in chronic arthritic diseases. PGs are products of the cyclooxygenase $(\mathrm{COX})^{1}$ pathway of arachidonic acid metabolism. Two isoforms of the COX enzyme have recently been identified. COX-1 is constitutively expressed in a variety of cells and tissues (5). The other isoform, COX-2, is the product of an immediate early response gene in inflammatory cells. The expression of COX-2 is induced by endotoxins, mitogens, or cytokines including IL-1 and TNF- $\alpha$ in cultured macrophages, fibroblasts, endothelial cells, and chondrocytes (6-13). In addition, both IL-1 and TNF- $\alpha$ enhance production of $\mathrm{PGE}_{2}$ and $\mathrm{COX}-2$ by synoviocytes from rheumatoid arthritis and osteoarthritis patients (14-17). Induction of cellular COX-2 biosynthesis is inhibited by dexamethasone (10, 13-16, 18-21), suggesting that endogenous corticosteroids may exert some negative regulatory effects on local inflammatory $\mathrm{PG}$ production.

Regulation of COX-2 gene expression has been documented in both human and rodent synovial tissues. Before the identification of selective probes for each $\mathrm{COX}$ isoform, Sano et al. (22) observed intense intracellular COX immunostaining in synovial lining cells, fibroblasts, and macrophages of rheumatoid arthritis patients, while osteoarthritis synovia showed weak and diffuse COX staining and staining was absent in normal synovial tissue. COX immunostaining was also observed in inflamed paw tissue from Lewis rats with streptococcal cell wall- or adjuvant-induced arthritis; staining was absent in normal paw tissue. The level of COX expression was found to parallel the development of clinical disease and correlate with synovial mononuclear cell infiltration in experimentally induced arthritis. Furthermore, this study showed that treatment with dexamethasone prevented the high level expression of COX protein in synovial tissue, suggesting that the inducible COX-2 enzyme is selectively upregulated in arthritic tissues. Crofford et al. (14) extended those findings by demonstrating that IL-1 $\beta$ enhanced de novo synthesis of COX-2 but not COX-1 mRNA and protein in rheumatoid synovial explants and cultured rheumatoid synoviocytes. Selective upregulation of COX-2 mRNA and protein has also recently been demonstrated in rodent air pouch models of acute granulomatous inflammation $(23,24)$. Taken together, these findings suggest that the enhanced production of PGs in both acutely and chronically inflamed tissues results from selective, local upregulation of COX-2 biosynthesis.

Nonsteroidal antiinflammatory drugs (NSAIDs), including indomethacin, are effective antiinflammatory and analgesic agents commonly used in the treatment of rheumatoid arthritis and osteoarthritis. NSAIDs inhibit PG formation through inhibition of both the COX-1 and COX-2 enzymes $(25,26)$. Longterm NSAID treatment is often limited, however, by gastrointestinal ulcerogenicity that may result from the suppression of

1. Abbreviations used in this paper: COX, cyclooxygenase; NSAID, nonsteroidal antiinflammatory drug. 
physiological PG production in these tissues. We have recently demonstrated the ability of a selective COX-2 inhibitor to block PG production (23) and acute tissue inflammation (27) in vivo at dosages that do not affect stomach $\mathrm{PG}$ production, suggesting that COX-2 inhibitors may provide a safer therapeutic alternative to NSAIDs. In this report, we tested the hypothesis that inflammatory PG production in chronic arthritis is regulated through selective upregulation of COX-2 in synovial tissue. We used the Lewis rat model of adjuvant-induced arthritis to survey the expression of COX-1 and COX-2 throughout the disease process and to examine the therapeutic antiinflammatory effects of the selective COX-2 inhibitor SC-58125. Our data indicate that COX-2 but not COX-1 is upregulated in paw tissue concomitant to the development of edema in this model and that selective inhibition of $\mathrm{COX}-2$ rapidly reverses PG production and edema in arthritic paws. In addition, selective inhibition of COX-2 activity downregulates COX-2 and IL-6 production in arthritic paws and suppresses the systemic production of IL-6 induced by adjuvant.

\section{Methods}

Induction of arthritis. Arthritis was induced in male Lewis rats (125$150 \mathrm{~g}$; Harlan Sprague Dawley, Indianapolis, IN) by injection of $1 \mathrm{mg}$ of $M$. butyricum (Difco Laboratories Inc., Detroit, MI) in $50 \mu \mathrm{l}$ of mineral oil (Mallinkrodt, Paris, KY) into the right hind footpad (28). $14 \mathrm{~d}$ after injection of adjuvant, the contralateral left footpad volume was measured with a water displacement plethysmometer. Animals with paw volumes $0.37 \mathrm{ml}$ greater than normal paws were then randomized into treatment groups. Drug administration was begun on day 15 post-adjuvant injection and continued until final assessment on day 25. During this period contralateral paw volume measurements were taken intermittently. Some animals were also killed such that the left (contralateral) paw could be examined histologically and tissue levels of PG, COX, and cytokines could be measured. The typical increase in contralateral paw volume measured on day 25 ranged from 1.4 to $1.9 \mathrm{ml}$

Drug treatment. Dexamethasone and indomethacin were purchased from Sigma Chemical Co., St. Louis, MO. The selective inhibitor of COX-2, SC-58125: \{1-[(4-methylsulfonyl)phenyl]-3-trifluoromethyl-5-[(4-fluoro)phenyl] pyrazole $]$ was synthesized at G.D. Searle \& Co. (St. Louis, MO). SC-58125 potently inhibits the recombinant mouse COX-2 enzyme $\left(\mathrm{IC}_{50}=0.07 \mu \mathrm{M}\right)$ without inhibiting COX-1 $\left(\mathrm{IC}_{50}>100 \mu \mathrm{M}\right)(27)$. SC-58125 potently inhibits COX-2 in IL-1stimulated human fibroblasts $\left(\mathrm{IC}_{50}=0.09 \mu \mathrm{M}\right)$ without affecting human platelet COX-1 $\left(\mathrm{IC}_{50}=8.8 \mu \mathrm{M}\right)$. Oral administration of SC-58125 to Lewis rats at a dosage of $3 \mathrm{mg} / \mathrm{kg}$ has no effect on physiological PG production in the stomach (27) or on platelet COX-1 activity, measured ex vivo as A23187-induced thromboxane B2 (TxB2) production in whole blood. Compounds were prepared as a suspension in $0.5 \%$ methylcellulose, $0.025 \%$ Tween 80 (Sigma Chemical Co.). Animals were dosed twice daily by gavage at the indicated dosages in a volume of $1.0 \mathrm{ml} / \mathrm{d}$.

Paw sample preparation. After death, paws from arthritic and normal animals were amputated above the ankle, degloved, and snapfrozen in liquid nitrogen. Frozen paws were pulverized in a liquid nitrogen bath and divided into aliquots for extraction and analysis of PG, COX, and cytokine mRNAs and COX-2 protein. Samples were stored at $-70^{\circ} \mathrm{C}$ until used.

$R N A$ preparation and nuclease protection analysis. Samples of total RNA (5 $\mu \mathrm{g})(29)$ were hybridized with ${ }^{32}$ P-labeled antisense RNA probes. Specific mRNAs were quantified by nuclease protection using an Ambion RPA II ${ }^{\mathrm{TM}}$ kit (Ambion Inc., Austin, TX) as previously described (23). The rat COX-2 probe was graciously provided by $\mathrm{P}$. Worley, Johns Hopkins School of Medicine, Baltimore, MD. cDNA fragments of rat COX-1 (23), IL-6, and TNF- $\alpha$ were cloned by reverse transcriptase-PCR amplification from RNA obtained from carrageenan-stimulated air pouch tissue. Oligonucleotide primers were as follows: rat IL-6 forward GATCGACCTGGAGACTTCACAGAGGATACC and reverse GATCGACCATGGTTATATCCAGTTTGGAAGCATCC; rat TNF- $\alpha$ forward GATCGAAGCTTCATGGATCTCAAAGACAACC and reverse GATCGAGGATCCAGGGCTTGAGCTCAGCTCC. The rat GADPH template was purchased from Ambion Inc. Fragments were subcloned into pGEM $^{\mathrm{TM}}$ vectors (Promega Corp., Madison, WI). Antisense probes were transcribed using the appropriate RNA polymerase from plasmid templates linearized with enzymes that cut in the poly-linker adjacent to the $5^{\prime}$ end of the insert. Probes were synthesized using reagents from Promega and $\alpha\left[{ }^{32} \mathrm{P}\right] \mathrm{CTP}$ from New England Nuclear (Boston, MA). Relative intensities of each RNA were determined using a phosphorimager (Molecular Dynamics Inc., Sunnyvale, CA).

$C O X-2$ protein extraction and analysis. The mouse COX-2-specific L8 and R6 mouse mAbs (30) were produced by J. Pegg at G.D. Searle \& Co. Both L8 and R6 antibodies demonstrate $>1,000$-fold selectivity for mouse COX-2 compared to mouse COX-1 in solidphase capture RIAs and in competition binding RIAs (30). Pulverized frozen paw tissue (0.3-1 g) was added to $2 \mathrm{ml}$ of PBS containing $1 \%$ CHAPS (Sigma Chemical Co.). The tissue was solubilized for $24 \mathrm{~h}$ at $4^{\circ} \mathrm{C}$ with gentle rocking and then centrifuged at $200 \mathrm{~g}$ for $15 \mathrm{~min}$ to clear cell debris. COX-2 protein was quantified by ELISA (30). Microwell plates (Dynatek Laboratories Inc., Chantilly, VA) were coated with $200 \mu \mathrm{l}$ of mouse anti-mouse COX-2 mAb L8 $(1 \mu \mathrm{g} / \mathrm{ml}$ in borate-buffered saline) for $1 \mathrm{~h}$ and then blocked with $1 \%$ BSA in PBS containing $0.5 \%$ Tween 20 . Plates were washed three times with $0.5 \%$ Tween-PBS, and $50 \mu \mathrm{l}$ of a purified mouse COX-2 standard (provided by J. Gierse, G.D. Searle \& Co.) or tissue extract was added for $1 \mathrm{~h}$. Plates were again washed, and $200 \mu \mathrm{l}$ of horseradish peroxidase-conjugated R6 anti-mouse COX-2 mAb $(10 \mu \mathrm{g} / \mathrm{ml})$ was added for $1 \mathrm{~h}$. After thorough washing, $200 \mu \mathrm{l}$ ABTS (2,2'-azino-di[3ethylbenzthiazoline sulfonate (6)]) substrate (Kirkegaard and Perry Laboratories, Inc., Gaithersburg, MD) was added, and absorbance was measured at $405 \mathrm{~nm}$. The level of COX-2 protein in each sample was estimated by comparison of optical density to that of a COX-2 standard. The sensitivity of the COX-2 ELISA was $6.25 \mathrm{ng} / \mathrm{ml}$. Total sample protein was determined using the DC Protein Assay Kit (BioRad Laboratories, Hercules, CA), and COX-2 protein levels were expressed as nanograms COX-2 per milligram protein.

Prostaglandin extraction and analysis. Frozen paw tissue $(\sim 0.5 \mathrm{~g})$ was homogenized by polytron in $1 \mathrm{ml}$ methanol and again after the addition of $1 \mathrm{ml}$ water. The samples were adjusted to $10 \%$ methanol with water and allowed to precipitate on ice for $20 \mathrm{~min}$. Precipitated material was pelleted by centrifugation at $4^{\circ} \mathrm{C}$ for $20 \mathrm{~min}$. The supernatants were applied to a C-18 Sep-Pak cartridge (Waters Division of Millipore Corporation, Millford, MA) that was preconditioned with methanol followed by water. After loading the supernatants, the columns were sequentially washed with water, $10 \%$ methanol, and petroleum ether. The samples were eluted with methyl formate and evaporated under nitrogen. Samples were reconstituted in ELISA buffer and assayed for PGE $\mathrm{P}_{2}$ by ELISA (Cayman Chemicals, Ann Arbor, MI). The sensitivity of the $\mathrm{PGE}_{2}$ ELISA was $20 \mathrm{pg} / \mathrm{ml}$.

$I L-6$ bioassay. Rat blood was obtained from the retroorbital sinus and allowed to clot for $1 \mathrm{~h}$ at room temperature. Serum was recovered and frozen at $-70^{\circ} \mathrm{C}$ until assayed. Serum samples were assayed for their ability to support the proliferation of the IL-6-dependent 7TD1 plasmacytoma cell line as previously described (31). Results were estimated by four parameter regression of best line fit to a standard curve using recombinant mouse IL-6 (Genzyme Corp., Cambridge, MA) and expressed as units per milliliter. $1 \mathrm{U} / \mathrm{ml}$ produced half-maximal cell proliferation and was equivalent to $\sim 10 \mathrm{pg} / \mathrm{ml}$ of IL- 6 .

Histological evaluation of hind limb joints from arthritic paws. The left hind limb was removed below the stifle joint, degloved, and fixed in $1 \%$ formaldehyde in saline. The limbs were decalcified, processed, embedded in paraffin, sectioned, and stained with hematoxy- 

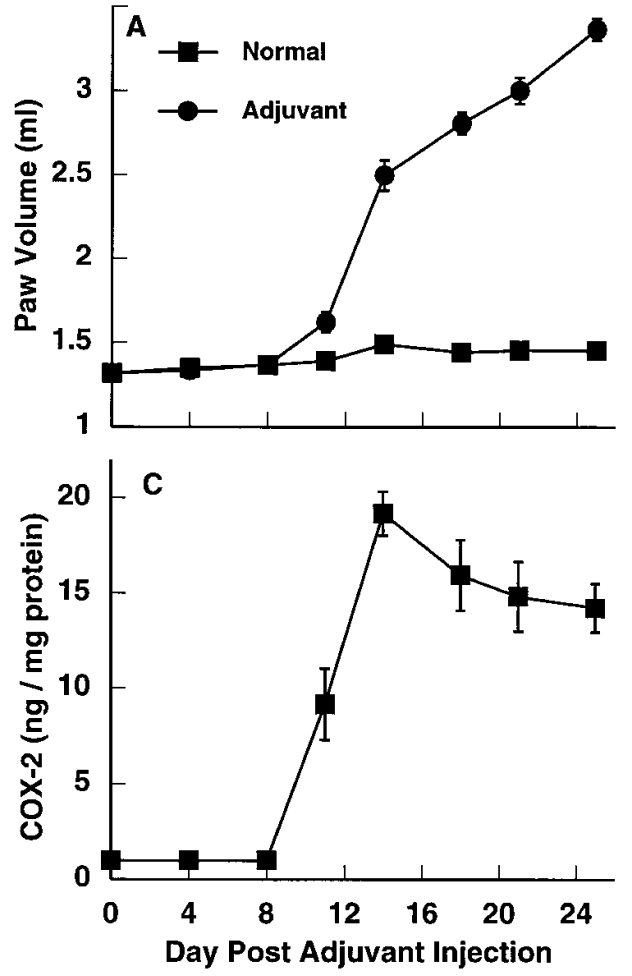
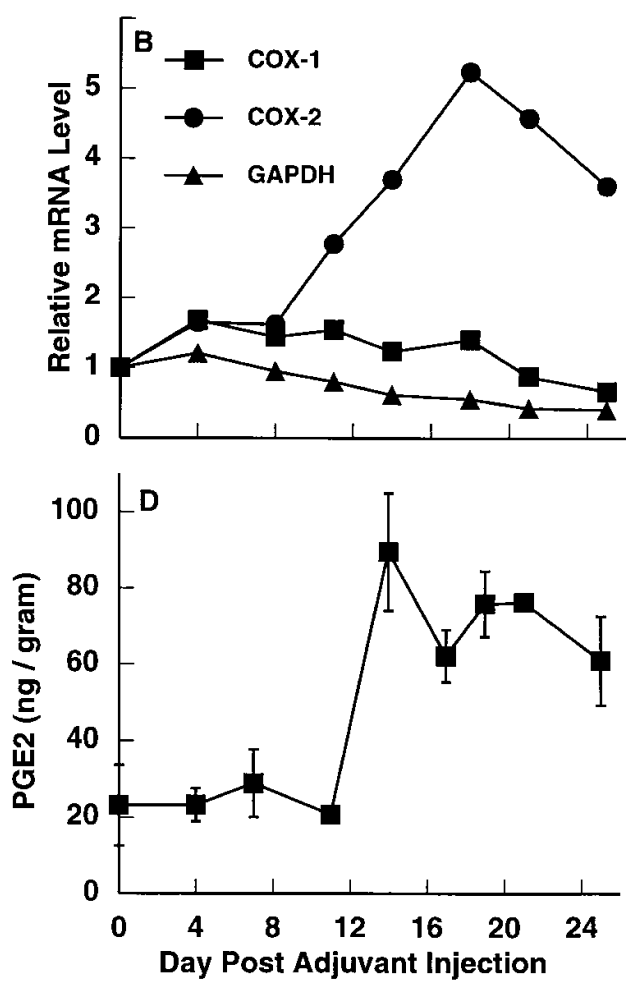

Figure 1. Induction of paw edema, COX-2 mRNA and protein, and $\mathrm{PGE}_{2}$ during adjuvant-induced arthritis. On day $0, M$. butyricum was injected subcutaneously in the plantar surface of the right hindpaw. At intervals thereafter, edema in the contralateral paw was measured as increased paw volume $(A)$ by plethysmometry. Paw tissue samples were also recovered for extraction and analysis. $B$ shows the levels of COX-1 (squares), COX-2 (circles), and GADPH (triangles) mRNAs detected in paw extracts by nuclease protection analysis. The levels of $\mathrm{COX}-2$ protein (ng/mg protein; $C$ ), and $\mathrm{PGE}_{2}$ (nanogram per gram paw tissue; $D$ ) in tissue extracts were determined by ELISAs. Data is presented as the group mean $\pm \operatorname{SEM}(n=3$ animals per group). lin and eosin. Sections of the paw were made in a mid-sagittal plane. Articulations of the tarsal and metatarsophalangeal joints were examined microscopically. Within each joint the synovium, cartilage, bone and soft tissue were examined for synovial hyperplasia, inflammation, bone and cartilage destruction, edema and pannus formation.

\section{Results}

Expression of $C O X-2$ and production of $P G E 2$ in rat adjuvant arthritis. The temporal relationship between COX expression,
PG production, and the development of arthritis was examined in adjuvant-injected Lewis rats and is shown in Fig. 1. An increase in contralateral paw volume was evident 11-14 d after adjuvant injection (Fig. $1 \mathrm{~A}$ ). Paw edema occurred concomitant with or immediately after the rapid induction of COX-2 mRNA, COX-2 protein, and $\mathrm{PGE}_{2}$ in the affected paws (Fig. $1, B-D$, respectively). The level of COX-2 mRNA increased four to fivefold over levels found in normal paws and was sustained through day 25, whereas the level of COX-1 mRNA increased less than twofold. The amount of COX-2 protein in af-

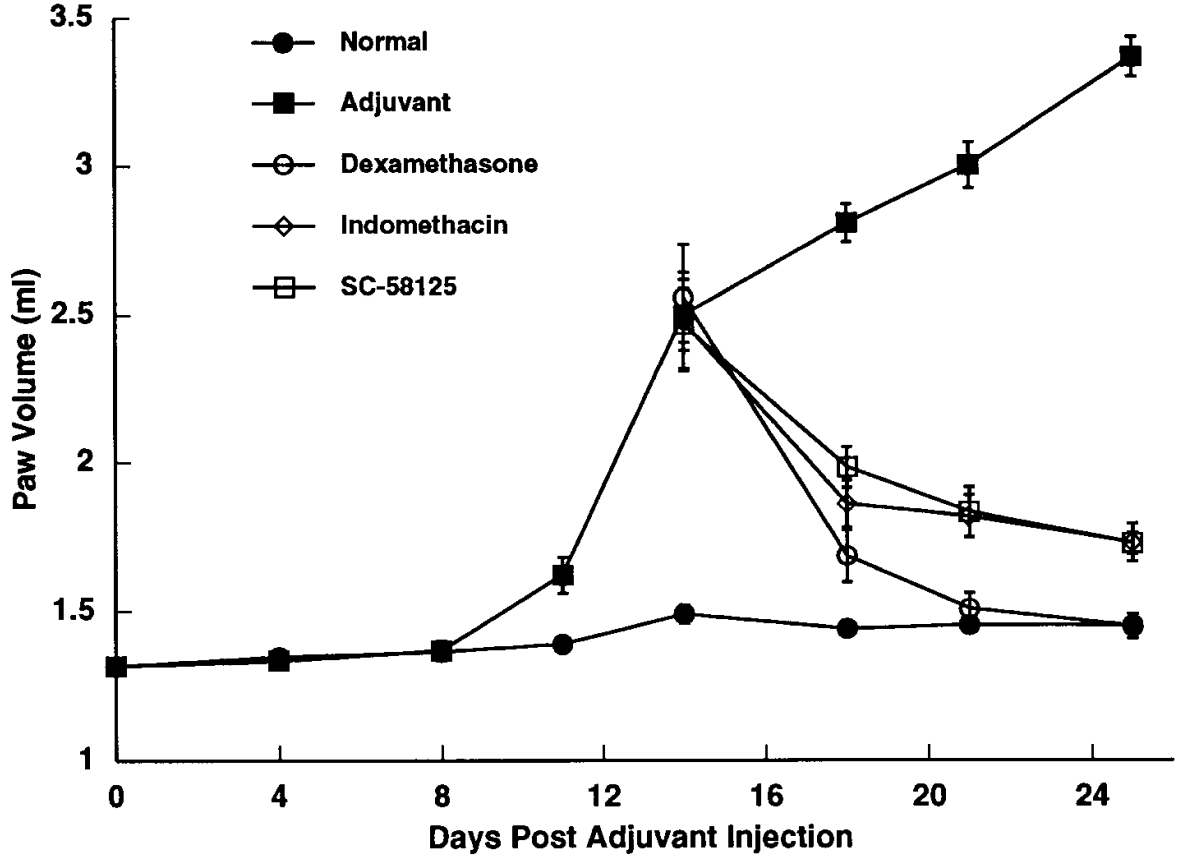

Figure 2. Reversal of paw edema after oral administration (b.i.d., i.g.) of SC58125 (3 mg/kg; open squares), indomethacin $(2 \mathrm{mg} / \mathrm{kg}$; open diamonds $)$, or dexamethasone $(0.1 \mathrm{mg} / \mathrm{kg}$; open circles $)$. Male Lewis rats were injected with $M$. butyricum on day 0 , and arthritic animals were randomized into treatment groups on day 14. Administration of compounds began on day 15. At intervals thereafter, edema in the contralateral paw was measured as increased paw volume by plethysmometry. The paw volumes recorded for normal (closed circles) and injected, vehicle-treated (closed squares) control animals are included for comparison. Data is presented as group mean \pm SEM ( $n=8$ animals per group). 
fected paws increased dramatically between days 8 and 14 and was accompanied by a sharp three to sixfold increase in the level of $\mathrm{PGE}_{2}$ in the paw; elevated levels of both COX-2 and $\mathrm{PGE}_{2}$ were sustained through day 25 . These data indicate that the development of arthritis was associated with selective upregulation of COX-2 mRNA and protein biosynthesis and production of $\mathrm{PGE}_{2}$ in the affected paw tissue.

Effect of SC-58125 on paw inflammation and PGE2 production in arthritic paws. We next evaluated the antiinflammatory effects of a selective inhibitor of COX-2, SC-58125, on established arthritis. As shown in Fig. 2, oral administration of SC-58125 (3 mg/kg) to arthritic rats rapidly reversed paw edema as did indomethacin and dexamethasone. After $10 \mathrm{~d}$ of treatment paw swelling was reduced in the SC-58125 treated animals by $80-85 \%$ relative to the paw volume of vehicletreated animals (Fig. $3 \mathrm{~A}$ ). The antiinflammatory effect of SC58125 was equivalent to that observed after treatment with indomethacin $(2 \mathrm{mg} / \mathrm{kg})$, while dexamethasone $(0.1 \mathrm{mg} / \mathrm{kg})$ inhibited paw edema by $95-100 \%$. For all treatments, the reduction in paw edema was associated with a pharmacological reduction in PG production in arthritic paws (Fig. $3 \mathrm{~B}$ ). Treatment with SC-58125 reduced the level of $\mathrm{PGE}_{2}$ in arthritic paws to near normal levels as did dexamethasone, suggesting that adjuvant-induced PG production is primarily mediated by $\mathrm{COX}-2$ in the paw.

Effect of SC-58125 on expression of COX-2 $m R N A$ and protein in arthritic paws. Unexpectedly, treatment of arthritic rats with SC-58125 decreased the level of COX-2 protein in arthritic paws (Fig. $3 \mathrm{C}$ ), as did indomethacin. Inhibition of $\mathrm{PG}$ production in the paws by the COX inhibitors was associated with a $>70 \%$ decrease in the level of COX-2 protein measured at day 25, suggesting that PG upregulate local COX-2 expression in the inflamed joint. The production of COX-2 protein was also attenuated by treatment with the glucocorticoid dexamethasone (Fig. $3 C$ ). The mechanism by which these inhibitors suppressed COX-2 protein production was further investigated by determining the steady state level of COX-2 mRNA in arthritic paws after treatment. SC-58125 and indomethacin dramatically reduced the level of COX-2 mRNA measured in arthritic paws on day 25 without affecting the level of COX-1 mRNA (Fig. 4). As expected, treatment of arthritic rats with dexamethasone also reduced the level of COX-2 but not COX-1 mRNA in affected paws.

Effect of SC-58125 on adjuvant-induced expression of TNF- $\alpha$ and $I L-6$. Since proinflammatory cytokines such as TNF- $\alpha$ and IL-1 are known to induce expression of COX-2 in synovial cells in vitro, we examined whether the treatment-related decreases in COX-2 production were associated with decreased adjuvant-induced cytokine production in arthritic paws. As shown in Fig. 4, high levels of TNF- $\alpha$ and IL-6 mRNAs were expressed in paws on day 25 , while very low levels of these mRNAs were detected in normal paw tissue. Treatment with SC-58125 markedly attenuated IL-6 mRNA expression in the paw but had no substantial effect on the level of $\mathrm{TNF}_{-} \alpha$ mRNA, suggesting that PGs selectively upregulate local cytokine expression in inflamed synovial tissue. The development of paw edema was associated with a dramatic increase in the level of IL-6 protein in serum (Fig. 5 A). The elevated level of IL-6 in the serum of arthritic rats persisted through day 25. Treatment with SC-58125 decreased the level of IL-6 in serum (Fig. $5 \mathrm{~B}$ ), indicating that COX-2-mediated PG production supports the systemic inflammatory cytokine response in adju-

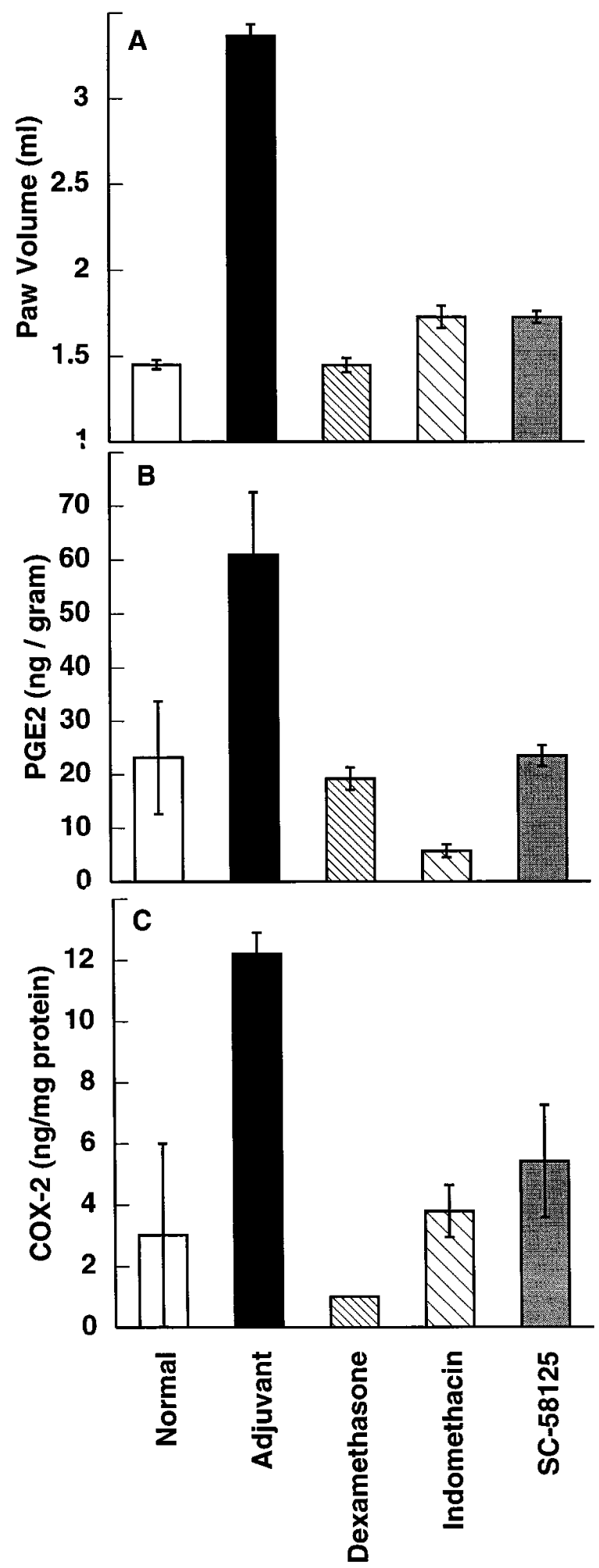

Figure 3. Decreased levels of adjuvant-induced edema, $\mathrm{PGE}_{2}$, and COX-2 protein in the paw after treatment with SC-58125, indomethacin, or dexamethasone. Arthritic rats were treated (b.i.d., i.g.) on days $15-25$. On day 25 , the volume of the contralateral paw $(A)$ was measured, and paw tissues were recovered for extraction and analysis. The levels of $\mathrm{PGE}_{2}$ (nanogram per gram paw tissue, $B$ ) and COX-2 protein (nanogram per milligram protein, $C$ ) in paw tissue were quantified by ELISAs. Data is presented as group mean $\pm \operatorname{SEM}(n=3$ animals per group). 


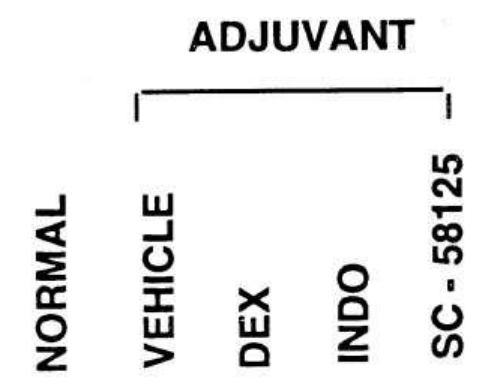

cox - 2

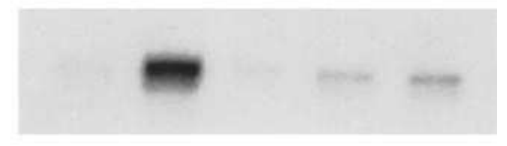

$\operatorname{cox}-1$

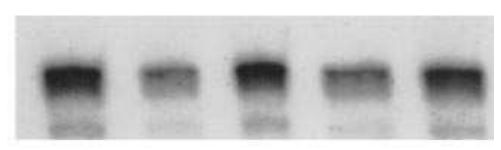

TNF- $\alpha$

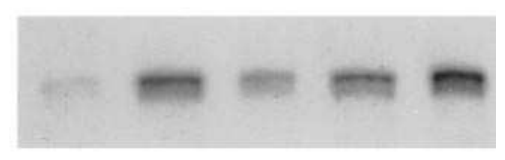

IL- 6

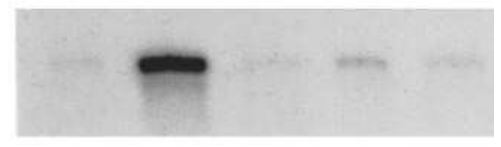

GAPDH

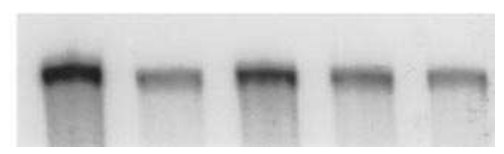

Figure 4. Nuclease protection analysis of adjuvant-induced COX-2, COX-1, TNF- $\alpha$, and IL- 6 mRNAs in normal paws and in arthritic paws after treatment (b.i.d., i.g.) on days 15-25 with SC-58125 (3 mg/ $\mathrm{kg})$, indomethacin $(2 \mathrm{mg} / \mathrm{kg})$, or dexamethasone $(0.1 \mathrm{mg} / \mathrm{kg})$. Paw tissues were recovered on day 25 post-adjuvant for extraction and analysis. The level of mRNAs were quantified by nuclease protection using specific rat antisense RNA probes; the level of GAPDH mRNA in each extract is shown for comparison.

vant arthritis. Indomethacin treatment produced results similar to that observed with SC-58125, confirming that COX-2 inhibitors have selective anticytokine effects in this model of arthritis. In contrast, treatment with dexamethasone suppressed the expression of both TNF- $\alpha$ and IL- 6 mRNAs in affected paws.

Effect of SC-58125 on joint histology. The antiinflammatory effects of SC-58125 were further examined by histological analysis of normal (Fig. $6 A$ ) versus arthritic paws obtained on day 25 after adjuvant injection (Fig. 6 B). Adjuvant-injected paws developed significant arthritic pathology to varying degrees in numerous joints. Significant cellular infiltration of the joints was apparent at day 14 without evidence of cartilage or bone destruction (not shown). At day 25 after adjuvant injection, severe inflammation was evident in the hard tissue of the
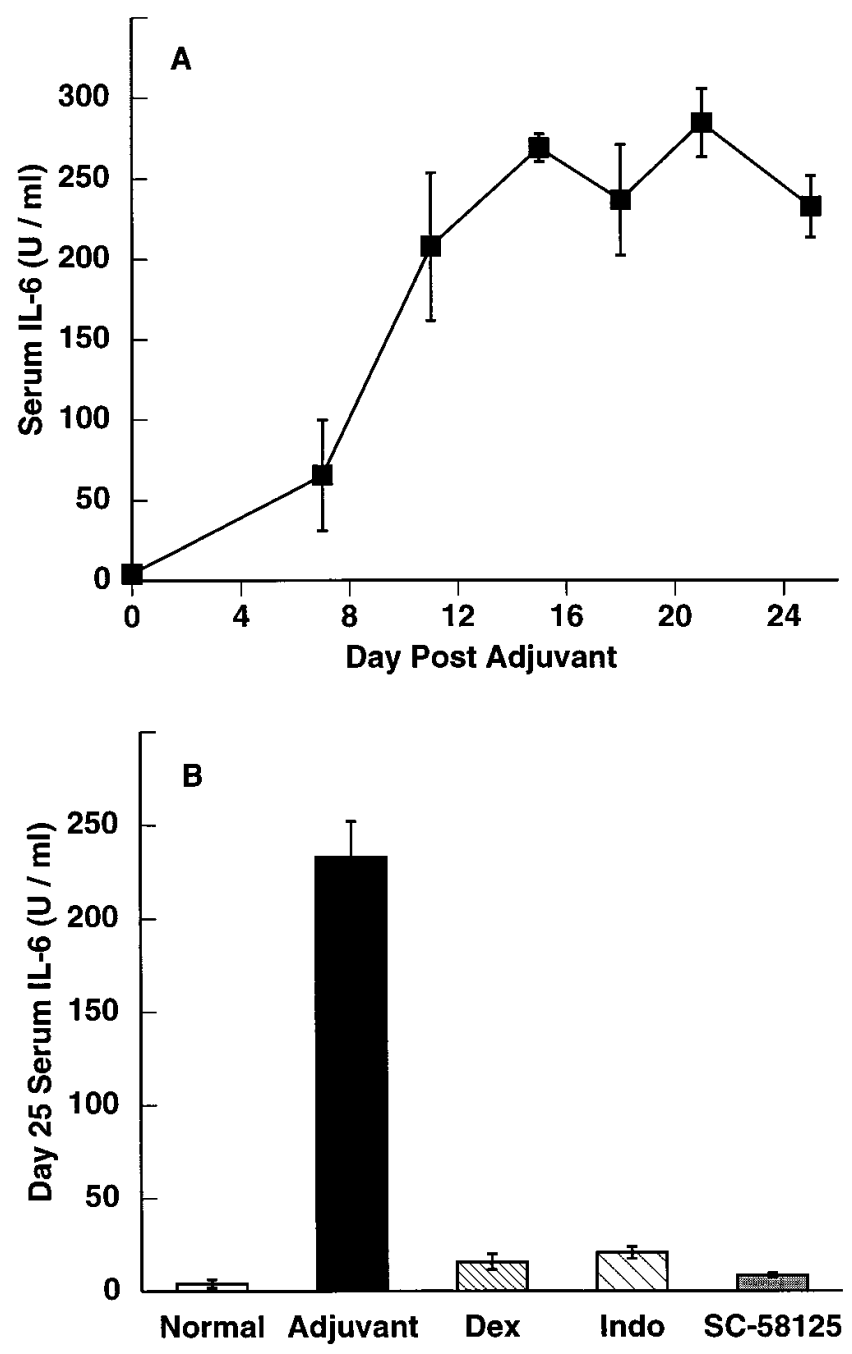

Figure 5. Elevation of IL-6 in the serum in arthritic rats and inhibition of systemic IL-6 production by treatment with SC-58125 (3 mg/ $\mathrm{kg})$, indomethacin $(2 \mathrm{mg} / \mathrm{kg})$, or dexamethasone $(0.1 \mathrm{mg} / \mathrm{kg})$. Male Lewis rats were injected with $M$. butyricum on day 0 . At intervals thereafter, serum samples were collected for quantitation of IL-6 bioactivity $(A)$. Arthritic rats were treated (b.i.d., i.g.) on days $10-25$, and the effect of treatment on the level of serum IL-6 bioactivity was determined on day $25(B)$. IL- 6 bioactivity $(\mathrm{U} / \mathrm{ml})$ was determined by support of murine 7TD1 cell proliferation and quantified by comparison to recombinant mouse IL-6. Data is presented as group mean $\pm \operatorname{SEM}(n=3$ animals per group).

bone and joint and the surrounding soft tissue. Soft tissue pathology consisted of extensive neutrophil and macrophage infiltration, and cartilage and muscle destruction. The subchondral bone in most joints was severely eroded by abundant osteoclasts. Paws from animals treated with SC-58125 (Fig. 6 $C$ ) or indomethacin (Fig. 6D) on days 15-25 showed a reduced but persistent inflammatory cell infiltrate. However, the number of osteoclasts present in the subchondral bone, tissue edema, and bone erosion in the paws were markedly reduced by both treatments, indicating that a selective inhibitor of COX-2 was as effective in retarding synovial inflammation and joint destruction as a nonselective COX inhibitor NSAID. Treatment with SC-58125 or indomethacin resulted in preservation of hyaline in the articular cartilage and a well defined tidemark separating the calcified cartilage. In addition, the 


\section{Normal}

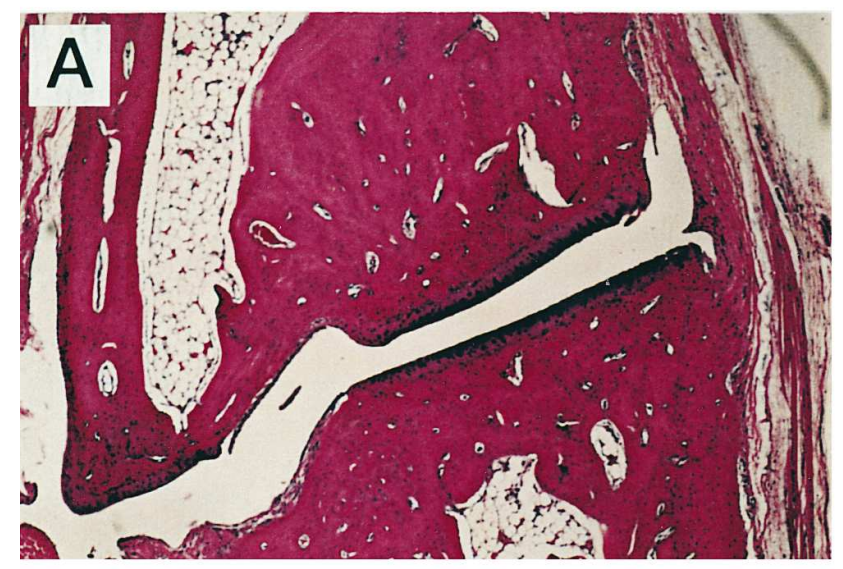

\section{SC-58125}

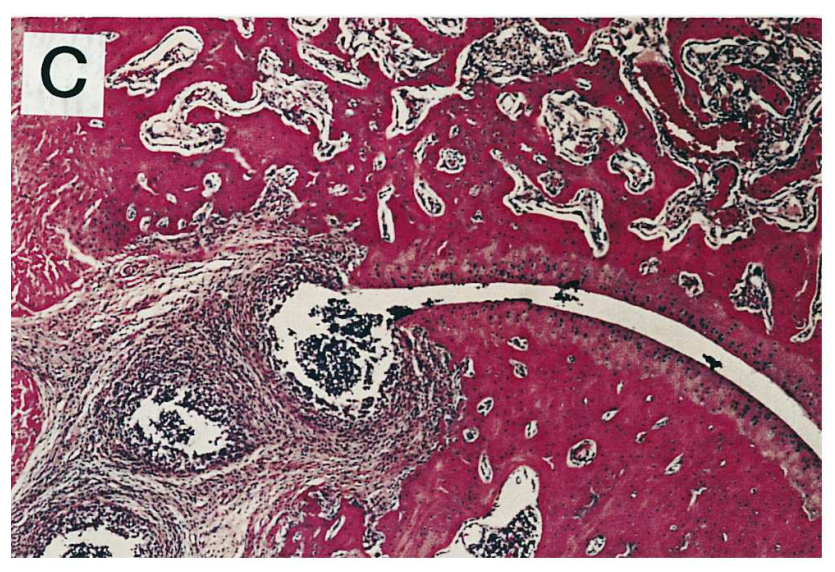

\section{Dexamethasone}

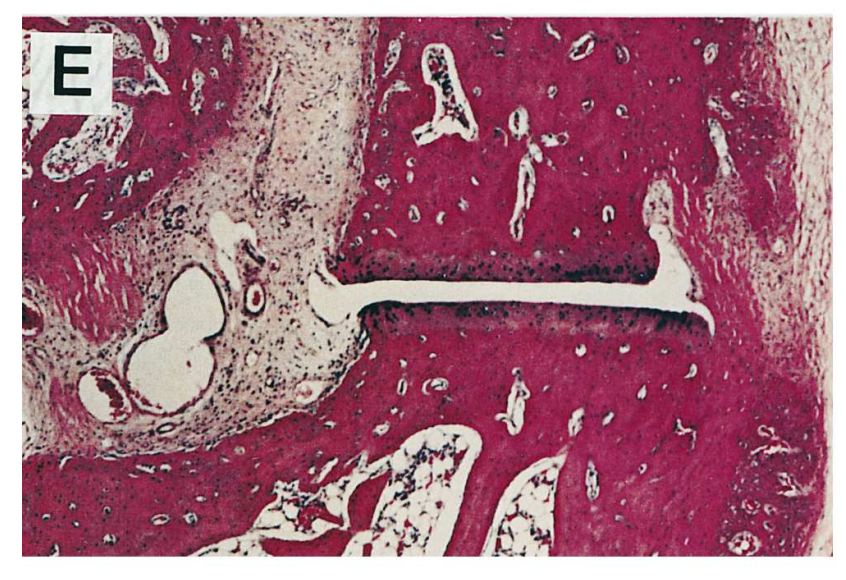

subchondral bone was intact, and the number of osteoclasts in the subchondral and trabecular bone space was greatly reduced. Treatment with dexamethasone over the same period almost completely abolished the cellular infiltrate in the joint and restored normal joint morphology.

\section{Untreated}

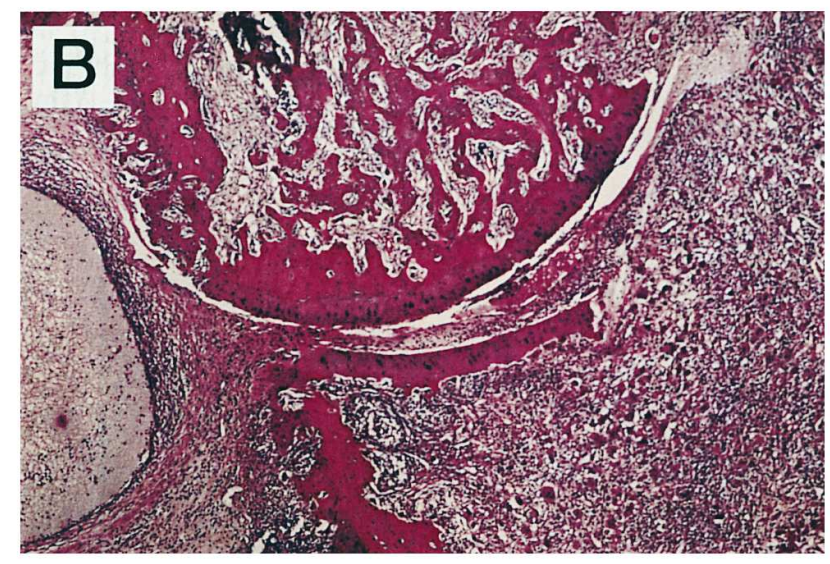

\section{Indomethacin}

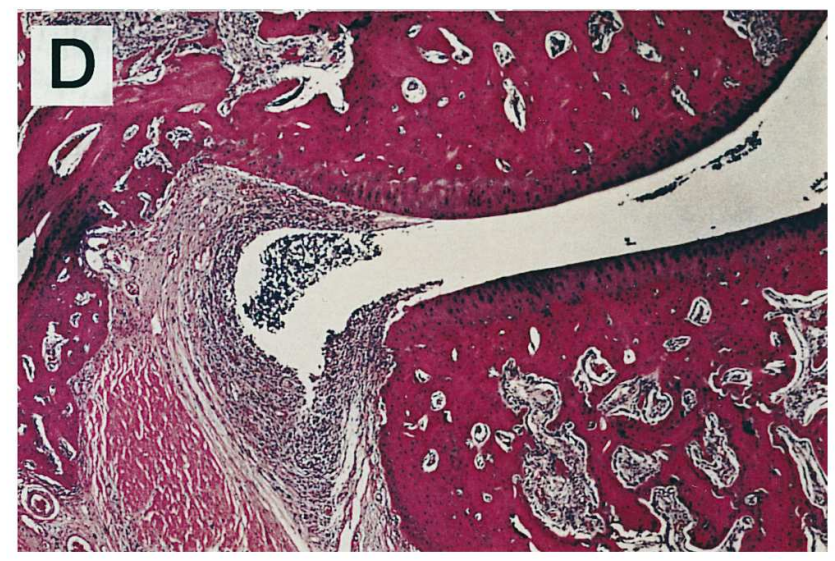

Figure 6. Composite photomicrograph of the histology of tarsal and metatarsophalangeal joints from normal rat paws $(A)$ or arthritic paws taken on day 25 after no treatment $(B)$, or after $10 \mathrm{~d}$ of treatment with SC-58125 $(C)$, indomethacin $(D)$, or dexamethasone $(E)$. The massive cellular infiltrate, tissue inflammation, pannus, and cartilage and bone erosion evident in the injected, untreated paws are typical features of the joint destruction observed at day 25. Treatment of the rats with SC-58125 or indomethacin on days 15-25 after adjuvant injection reduced the cellular infiltrate and soft tissue inflammation and improved joint morphology. Treatment with dexamethasone produced a more marked reduction in inflammatory infiltrate and improvement in both joint and bone morphology.

\section{Discussion}

The results of this study indicate that the development of synovial inflammation in experimentally induced arthritis is associated with a selective increase in the level of COX-2 mRNA 


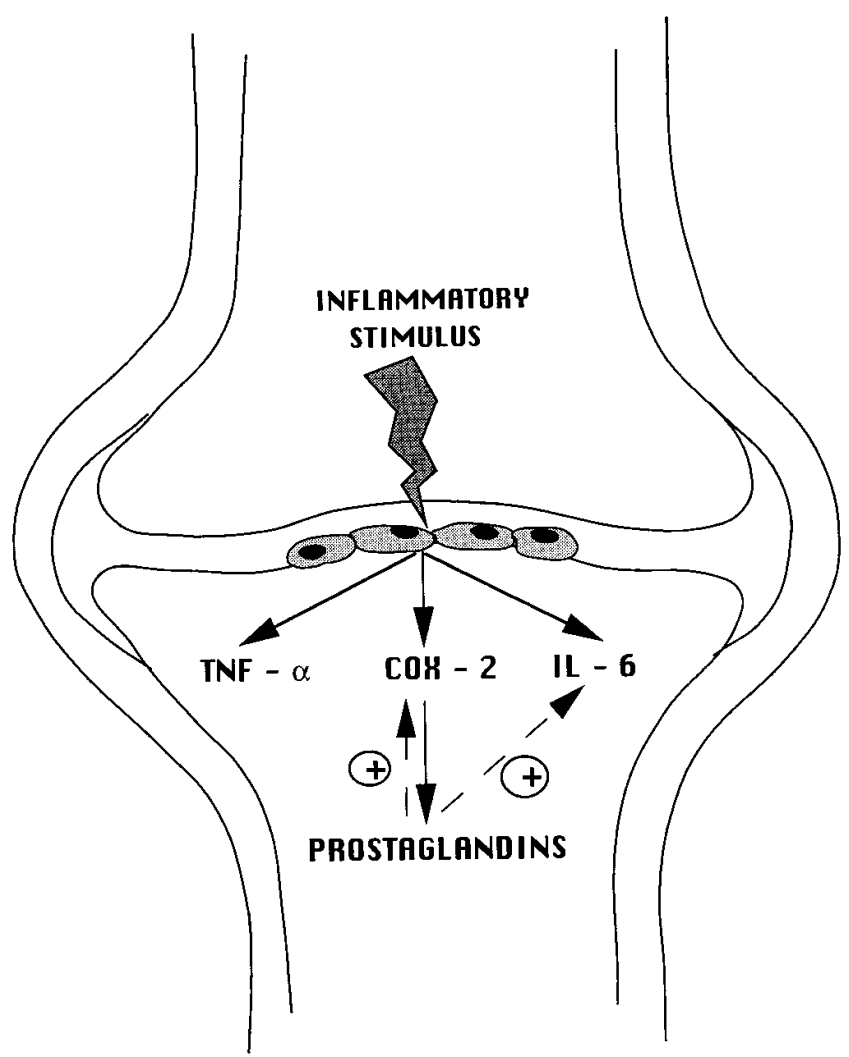

Figure 7. Model for regulation of PG, COX-2, and cytokine expression in arthritic synovial tissue. Stimulation of synoviocytes leads to TNF- $\alpha$ release and recruitment of inflammatory cells to the affected joint. Resident and recruited inflammatory cells produce COX-2 and IL-6. COX-2-derived PGs feed back to upregulate the production of COX-2 and IL-6 in a para- or autoregulatory fashion without affecting the level of TNF- $\alpha$.

and protein in affected tissues. This result extends the findings reported by Sano et al. (22) by identifying COX-2 as the induced COX isoform. Our result also confirms the observation reported by Crofford et al. (14) indicating that proinflammatory stimuli upregulate synovial cell production of functional COX-2 enzyme without modulating the production of COX-1. The earliest indicators of the systemic response to adjuvant were the appearance of IL- 6 in the serum and increased levels of TNF- $\alpha$, IL- 6 , and COX-2 mRNAs and COX-2 protein in noninjected paws; the level of COX-1 mRNA in the paws was relatively unchanged throughout the course of the disease. While our data do not directly demonstrate the induction of COX-2 transcription in the affected paws, Sano et al. (22) found high level COX protein expression in both the perivascular infiltrating macrophages and in resident synovial cells in this model, suggesting that de novo synthesis of COX-2 is upregulated in the inflamed synovia. The regulation of COX-2 gene expression involves both transcriptional and translational mechanisms (32), but details of the mechanisms remain elusive. Ristimaki et al. (33) recently showed that IL-1 $\alpha$ induces a rapid but transient activation of COX-2 transcription in inflammatory cells and stabilizes the COX-2 mRNA in the absence of transcription. It is likely that adjuvant induces the production of IL-1 as well as TNF- $\alpha$ in affected joints and that IL-1 plays an important role in the regulation of sustained COX-2 polypeptide synthesis in arthritic responses.
This study also provides insight into the proinflammatory activities of COX-2-derived PGs in established arthritis. Oral administration of the selective COX-2 inhibitor SC-58125 to arthritic animals rapidly reversed paw edema, reduced joint inflammation and returned $\mathrm{PGE}_{2}$ levels to normal. Furthermore, inhibition of COX-2 activity diminished the level of COX-2 mRNA in paw tissue without affecting the steady state level of COX-1 mRNA, suggesting that PGs enhance the local expression of COX-2 itself in inflamed synovial tissue. The antiinflammatory effects of SC-58125 were indistinguishable from the effects observed with indomethacin, a nonselective COX inhibitor, confirming that pharmacological inhibition of COX-2 underlies the suppression of PG production, edema, and COX-2 expression in adjuvant arthritis.

Inhibition of COX-2 activity also modulated local and systemic cytokine production in arthritic rats. The development of arthritis was associated with increased levels of TNF- $\alpha$ and IL-6 mRNAs in affected paws and systemic IL-6 production. Both cytokines have been shown to be produced spontaneously by rheumatoid arthritis synovial cells (34-37). Treatment of arthritic rats with SC-58125 or indomethacin markedly reduced the level of IL- 6 mRNA in affected paws. Inhibition of COX-2 activity also reversed systemic IL-6 production in arthritic animals, suggesting that PGs provide a costimulatory signal for both local and systemic IL-6 production in adjuvant arthritis. Partial inhibition of systemic IL- 6 production by treatment with indomethacin has been documented previously (38). Both enhancement and suppression of TNF- $\alpha$ production have been demonstrated to be dose dependently regulated by $\mathrm{PGE}_{2}$ and cAMP in rat peritoneal macrophages (39), but we observed no significant change in the level of TNF- $\alpha$ mRNA in the paws of rats treated with SC-58125 or indomethacin. In contrast, treatment with dexamethasone markedly reduced the levels of both TNF- $\alpha$ and IL- 6 mRNA in arthritic paws.

A short course of treatment with SC-58125 or indomethacin markedly reduced the cellular infiltrate in affected joints, inflammation of synovial tissue, and erosion of bone and cartilage. The ability of COX inhibitors to partially reduce the mononuclear infiltrate in arthritic joints could in part explain the observed reduction in the levels of COX-2 and IL- 6 proteins in the paw, but the residual macrophage infiltrate still evident after $10 \mathrm{~d}$ of treatment suggests that de novo COX-2 and IL-6 production in the synovium was suppressed. In contrast to the COX inhibitors, treatment of arthritic animals with dexamethasone almost completely abrogated cellular infiltration of the joint, restoring normal joint morphology. This additional antiinflammatory effect may reflect the ability of dexamethasone to modulate the cellular immune response to adjuvant and to suppress PG-independent proinflammatory cellular responses in established disease.

Taken together, our findings support a model (Fig. 7) in which adjuvant induces local TNF- $\alpha$, COX-2, and IL-6 production in the affected paws. COX-2-derived PGs appear to mediate a variety of proinflammatory effects in this model of arthritis, including enhancement of local plasma and cellular exudation and upregulation of IL-6 and COX-2 itself. Enhanced TNF- $\alpha$ expression did not correlate with COX-2 or IL-6 expression when PG synthesis was inhibited, however, suggesting that COX-2 and IL- 6 are not induced by TNF- $\alpha$ in the inflamed synovium. Additional studies will be needed to determine whether the expression of COX-2 or IL- 6 are dependent on IL-1 production in this model and whether PGs regulate 
the expression of IL-1 in inflamed synovial tissue. Overall, this study demonstrates that treatment of established adjuvant arthritis with a selective inhibitor of COX-2 produces antiinflammatory effects that are qualitatively and quantitatively comparable to the nonselective COX inhibitor indomethacin. These findings suggest that proinflammatory $\mathrm{PG}$ production in chronic synovial inflammation is mediated primarily by the activity of the induced COX-2 enzyme and that selective COX-2 inhibitors will likely be as effective as NSAIDs in the treatment of arthritic diseases.

\section{Acknowledgments}

We thank D. Edwards and Dr. R. Ornberg for assistance with immunohistochemical analyses. We also thank Drs. P. Manning, J. Portanova, K. Seibert, and W. Smith for their excellent critique.

\section{References}

1. Bombardieri, S., P. Cattani, G. Ciabattoni, O. Di Munno, G. Pasero, C. Patrono, E. Pinca, and F. Pugliese. 1981. The synovial prostaglandin system in chronic inflammatory arthritis: differential effects of steroidal and non-steroidal anti-inflammatory drugs. Br. J. Pharmacol. 73:893-901.

2. Davies, P., P.J. Bailey, M.M. Goldenberg, and A.W. Ford-Hutchinson. 1984. The role of arachidonic acid oxygenation products in pain and inflammation. Annu. Rev. Immunol. 2:335-357.

3. Davies, P., and D.E. MacIntyre. 1992. Prostaglandins and inflammation. In Inflammation: Basic Principles and Clinical Correlates. J.I. Gallin, I.M. Goldstein, and R. Snyderman, editors. Raven Press, Ltd., New York. 123-137.

4. Robinson, D.R., A.H. Tashjian, and L. Levine. 1975. Prostaglandin-stimulated bone resorption by rheumatoid synovia. A possible mechanism for bone destruction in rheumatoid arthritis. J. Clin. Invest. 56:1181-1188.

5. O'Neill, G., and A.F. Hutchinson, 1993. Expression of mRNA for cyclooxygenase-1 and cyclooxygenase-2 in human tissues. FEBS Lett. 330:156160.

6. Raz, A., A. Wyche, N. Siegel, and P. Needleman. 1988. Regulation of fibroblast cyclooxygenase synthesis by interleukin-1. J. Biol. Chem. 263:30223028.

7. Maier, J.A.M., T. Hla, and T. Maciag. 1990. Cyclooxygenase is an immediate early gene induced by interleukin-1 in human endothelial cells. J. Biol. Chem. 265:10805-10808.

8. Fletcher, B.S., D.A. Kujubu, D.M. Perrin, and H.R. Herschman. 1992. Structure of the mitogen-inducible TIS10 gene and demonstration that the TIS10-encoded protein is a functional prostaglandin $\mathrm{G} / \mathrm{H}$ synthase. J. Biol. Chem. 267:4338-4344.

9. O'Sullivan, M.G., F.H. Chilton, E.M. Huggins, Jr., and C.E. McCall. 1992. Lipopolysaccharide priming of alveolar macrophages for enhanced synthesis of prostanoids involves induction of a novel prostaglandin $\mathrm{H}$ synthase. $J$. Biol. Chem. 267:14547-14550.

10. Lee, S.H., E. Soyoola, P. Chanmugam, S. Hart, W. Sun, H. Zhong, S. Liou, D. Simmons, and D. Hwang. 1992. Selective expression of mitogen-inducible cyclooxygenase in macrophages stimulated with lipopolysaccharide. J. Biol. Chem. 267:25934-25938.

11. Jones, D.A., D.P. Carlton, T.M. McIntyre, G.A. Zimmerman, and S.M. Prescott. 1993. Molecular cloning of human prostaglandin endoperoxide synthase type II and demonstration of expression in response to cytokines. J. Biol. Chem. 268:9049-9054.

12. Hemple, S.L., M.M. Monick, and G.W. Hunninghake. 1994. Lipopolysaccharide induces prostaglandin $\mathrm{H}$ synthase-2 protein and mRNA in human alveolar macrophages and blood monocytes. J. Clin. Invest. 93:391-396.

13. Geng, Y., F.J. Blanco, M. Cornelisson, and M. Lotz. 1995. Regulation of cyclooxygenase-2 expression in normal human articular chondrocytes. J. Immunol. 155:796-801.

14. Crofford, L.J., R.L. Wilder, A.P. Ristimake, H. Sano, E.F. Remmers, H.R. Epps, and T. Hla. 1994. Cyclooxygenase-1 and -2 expression in rheumatoid synovial tissues. J. Clin. Invest. 93:1095-1101.

15. Szczepanski, A., T. Moatter, W.W. Carley, and M.E. Gerritsen. 1994. Induction of cyclooxygenase II in human synovial microvessel endothelial cells by interleukin-1: Inhibition by glucocorticoids. Arthritis \& Rheum. 37:495-503.

16. Angel, J., F. Berenbaum, C. Le Denmat, T. Nevalainen, J. Masliah, and C. Fournier. 1994. Interleukin-1-induced prostaglandin $\mathrm{E}_{2}$ biosynthesis in human synovial cells involves the activation of cytosolic phospholipase $\mathrm{A}_{2}$ and cyclooxygenase-2. Eur. J. Biochem. 226:125-131.

17. Seitz, M., P. Loetscher, B. Dewald, H. Towbin, M. Ceska, and M. Baggiolini. 1994. Production of interleukin-1 receptor antagonist, inflammatory chemotactic proteins, and prostaglandin E by rheumatoid and osteoarthritic synoviocytes. Regulation by IFN- $\gamma$ and IL-4. J. Immunol. 152:2060-2065.

18. Fu, J.-Y., J.L. Masferrer, K. Seibert, A. Raz, and P. Needleman. 1990 The induction and suppression of prostaglandin $\mathrm{H}_{2}$ synthase (cyclooxygenase) in human monocytes. J. Biol. Chem. 265:16737-16740.

19. Masferrer, J.L., B.S. Zweifel, K. Seibert, and P. Needleman. 1990. Selective regulation of cellular cyclooxygenase by dexamethasone and endotoxin in mice. J. Clin. Invest. 86:1375-1379.

20. O'Banion, M.K., H.B. Sadowski, V. Winn, and D.A. Young. 1991. A serum- and glucocorticoid-regulated 4-kilobase mRNA encodes a cyclooxygenase-related protein. J. Biol. Chem. 266:23261-23267.

21. Kujubu, D.A., and J.R. Herschman. 1992. Dexamethasone inhibits mitogen induction of the TIS10 prostaglandin synthase/cyclooxygenase gene. $J$. Biol. Chem. 267:7991-7994.

22. Sano, H., T. Hla, J.A. Maier, L.J. Crofford, J.P. Case, T. Maciag, and R.L. Wilder. 1992. In vivo cyclooxygenase expression in synovial tissues of patients with rheumatoid arthritis and osteoarthritis and rats with adjuvant and streptococcal cell wall arthritis. J. Clin. Invest. 89:97-108.

23. Masferrer, J.L., B.S. Zweifel, P.T. Manning, S.D. Hauser, K.M. Leahy, W.G. Smith, P.C. Isakson, and K. Seibert. 1994. Selective inhibition of inducible cyclooxygenase-2 in vivo is antiinflammatory and nonulcerogenic. Proc. Natl. Acad. Sci. USA. 91:3228-3232.

24. Vane, J.R., J.A. Mitchell, I. Appleton, A. Tomlinson, D. Bishop-Bailey, J. Croxtall, and D.A. Willoughby. 1994. Inducible isoforms of cyclooxygenase and nitric-oxide synthase in inflammation. Proc. Natl. Acad. Sci. USA. 91:20462050

25. Meade, E.A., W.L. Smith, and D.L. DeWitt. 1993. Differential inhibition of prostaglandin endoperoxide synthase (cyclooxygenase) isozymes by aspirin and other nonsteroidal anti-inflammatory drugs. J. Biol. Chem. 268:66106614.

26. O’Neill, G.P., J.A. Mancini, S. Kargman, J. Yergey, M.Y. Kwan, J.-P. Falgueyrat, M. Abramovitz, B.P. Kennedy, M. Ouellet, et al. 1994. Overexpression of human prostaglandin $\mathrm{G} / \mathrm{H}$ synthase- 1 and -2 by recombinant vaccinia virus: inhibition by nonsteroidal anti-inflammatory drugs and biosynthesis of 15 hydroxyeicosatetraenoic acid. Mol. Pharmacol. 45:245-254.

27. Seibert, K., Y. Zhang, K. Leahy, S. Hauser, J. Masferrer, W. Perkins, L. Lee, and P.C. Isakson. 1994. Pharmacological and biochemical demonstration of the role of cyclooxygenase 2 in inflammation and pain. Proc. Natl. Acad. Sci. USA. 91:12013-12017.

28. Billingham, M.E.J. 1983. Models of arthritis and the search for antiarthritic drugs. Pharmacol. \& Ther. 21:389-428.

29. Chomczynski, P., and N. Sacchi. 1987. Single-step method of RNA isolation by acid guanidinium thiocyanate-phenol-chloroform extraction. Anal. Biochem. 162:156-159.

30. Kaufmann, W.E., P.F. Worley, J. Pegg, M. Bremer, and P.C. Isakson. 1996. COX-2: a synaptically induced enzyme is expressed by excitatory neurons at postsynaptic sites in rat cerebral cortex. Proc. Natl. Acad. Sci. USA. 93:23172321

31. Van Snick, J., A. Vink, S. Cayphas, and C. Uyttenhove. 1987. Interleukin-HP1, a T cell-derived hybridoma growth factor that supports the in vitro growth of murine plasmacytomas. J. Exp. Med. 165:641-649.

32. Raz, A., A. Wyche, and P. Needleman. 1989. Temporal and pharmacological division of fibroblast cyclooxygenase expression into transcriptional and translational phases. Proc. Natl. Acad. Sci. USA. 86:1657-1661.

33. Ristimaki, A., S. Garfinkel, J. Wessendorf, T. Maciag, and T. Hla. 1994. Induction of cyclooxygenase-2 by interleukin-1 $\alpha$. J. Biol. Chem. 269:1176911775 .

34. Buchan, G., K. Barrett, M. Turner, D. Chantry, R.N. Maini, and M. Feldmann. 1988b. Interleukin-1 and tumour necrosis factor mRNA expression in rheumatoid arthritis: prolonged production of IL-1 $\alpha$. Clin. Exp. Immunol. 73: $449-455$.

35. Hirano, T., T. Matsuda, M. Turner, N. Miyasaka, G. Buchan, B. Tang, K. Sato, M. Shimizu, R. Maini, M. Feldmann, and T. Kishimoto. 1988. Excessive production of interleukin 6/B cell stimulatory factor-2 in rheumatoid arthritis. Eur. J. Immunol. 18:1797-1801.

36. Feldmann, M., F.M. Brennan, D. Chantry, C. Haworth, M. Turner, E. Abney, G. Buchan, K. Barrett, D. Barkley, A. Chu, M. Field, and R.N. Maini 1990. Cytokine production in the rheumatoid joint: implications for treatment. Ann. Rheum. Dis. 51:480-486.

37. Houssiau, F.A., J.-P. Devogelaer, J. Van Damme, C.N. De Deuxchaisnes, and J. Van Snick. 1988. Interleukin-6 in synovial fluid and serum of patients with rheumatoid arthritis and other inflammatory arthridies. Arthritis \& Rheum. 31:784-788.

38. Theisen-Popp, P., H. Pape, and R. Muller-Peddinghaus. 1992. Interleukin 6 (IL-6) in adjuvant arthritis of rats and its pharmacological modulation. Int. J. Immunopharmacol. 14:565-571.

39. Renz, H., J.-H. Gong, A. Schmidt, M. Nain, and D. Gemsa. 1988. Release of tumor necrosis factor- $\alpha$ from macrophages: enhancement and suppression are dose-dependently regulated by prostaglandin $\mathrm{E}_{2}$ and cyclic nucleotides. J. Immunol. 141:2388-2393. 